\title{
COURSE COHESION: AN ELUSIVE GOAL FOR TERTIARY EDUCATION
}

\author{
Nan Bahr \\ Faculty of Education \\ Queensland University of Technology, Australia \\ n.bahr@qut.edu.au \\ Margaret Lloyd \\ Faculty of Education \\ Queensland University of Technology, Australia \\ mm.lloyd@qut.edu.au
}

\begin{abstract}
A program's development and implementation in a higher education institution is usually launched with great fanfare, goodwill and a huge effort on the part of the whole development team to ensure a worthwhile cohesive set of learning experiences aligned to the desired course learning outcomes. It is often not long before the glue starts to come unstuck arising from staffing changes, subtle migration of course resources, opportunistic inclusions of "off the shelf" or unit based innovative teaching and learning approaches, and perhaps general poor attention to detail with regard to the impact of new introductions and electives. This paper presents an initial investigation into the elusive goal of achieving course cohesion. The authors consider building cohesion into a course as it is being designed through identified cohesion factors and in sustaining course cohesion through active leadership.
\end{abstract}

Keywords

curriculum, course evaluation, cohesion, leadership

\section{Introduction}

Designing a course ${ }^{1}$ at a university is the easy part. It is exciting, creative and collegiate. The development and implementation of new courses are surrounded with enthusiasm and a genuine sense of renewal. It provides an opportunity for faculty members to work together in genuinely collaborative and collegiate ways. The leader has a vehicle to pull an academic team together. The first year or so of implementation are heady days as the initial momentum and course cohesion are sustained. But then, almost inevitably, this dissipates as the "glue" of the initial design starts to come unstuck. The reasons for this are varied and may include staffing changes, subtle and incremental migration of course resources, opportunistic inclusions of "off the shelf" or unit based innovative teaching and learning approaches, and perhaps generally poor attention to detail with regard to the impact of new introductions and electives. It might also be contended that, given the focus on the individual in terms of teacher reflection (Massam, 2004) and personal feedback and evaluation, it is not surprising that academics begin to see themselves in Shulman's "pedagogical solitude" (1993). Whatever the cause, the effect is that the "parts" become more important than the whole and faculty lose sight of course outcomes. Academic work becomes more atomistic with an exclusive focus on a single unit of study rather than holistic, that is, on a course or working in

\footnotetext{
${ }^{1}$ In this paper a course is defined as a sequence of semester long units of study. The base element of a course is the unit, and students could engage in several units per semester of their course. For this paper a synonymous term for course is program.
} 
tandem with others. The leadership of the team has often dissipated and/or has focussed on pragmatic solutions to logistical crises rather than attention to the design vision.

While there may be other triggers (often external) for the redesign of courses, this paper will focus on the need for reconceptualisation and redesign imposed by the loss of course cohesion, what we are calling "course cohesion drift." The model posed in this paper emerged from a weariness and frustration with the cyclic process of course development, then course unravelling, and then, before long, a return to course development, ad infinitum. We believe that what is needed is a different conception of course leadership tied to a model for curriculum design, development and sustaining that extends the notion of constructive alignment (Biggs, 1999) into more holistic planning processes. The proposed model attends to what we have called cohesion factors and proposes tools such as snapshot and connection trees to inform the process of ongoing curriculum development. Critically, this model accepts and acknowledges that implementation and development processes will be "a continuing action learning cycle of reflection, application and evaluation” (Biggs \& Tang, 2007, p. 247). Established models presume that the process is a "oneoff” and that, once prescribed, curriculum remains static. For example, Johnson (1994) described curriculum development as comprising four linear stages of development: curriculum planning; ends-means specification; program implementation; and, classroom implementation. The difference in what is proposed here is that the process acknowledges the cyclic rather than linear nature and presumes that no component of a course is static.

This paper begins by establishing the need for course cohesion and presenting our model of cohesion factors, effectively a hypothesis of how a course of study might be designed to hold together. It then seeks to extend and test the model by asking senior academics about the overarching factor of leadership.

\section{Importance of cohesion}

It is important to preface the description of the model by identifying why "cohesion" is a critical element of course implementation. The answer lies in the descriptors which universities themselves accord to curriculum design. For example, Flinders University (South Australia) offered that:

Curriculum matters mainly because of its potential impacts on students. The fundamental purpose of curriculum development is to ensure that students receive integrated, coherent learning experiences that contribute towards their personal, academic and professional learning and development.

(Flinders University, 2009, para. 1)

Cohesion, in this statement, is equated with integration and coherence. The term, coherence, is elsewhere used to describe a curriculum in which "decision outcomes from the various stages of development are mutually consistent and complementary, and learning outcomes reflect curriculum aims" (Johnson, 1994, p. xiii). It is the prevention of gradual but incremental loss of cohesion - or the moving away from the intention and direction of the original design - that is the key focus of the model described in this paper. A delicate balance is needed between unwanted cohesion drift and a well managed course morphing in response to continual evaluation.

Starting with a cohesive design

The likelihood of a course retaining cohesion extends from the initial stages of its curriculum development. In most higher education institutions, curriculum development evolves as the various sequential processes of approval and accreditation, both internally and with external stakeholders, is negotiated. That is, the policy framework drives the course development. Courses that roll out their design in strict accordance with rigid policy guidelines and approval timelines tend to prioritise the pragmatics of course conduct including marketing and workload designations, but more particularly assessment types and modes, weightings, and timetabling demands.

If pragmatically built courses are not designed for cohesion as their most predominant feature, but are designed to meet regulations that almost inevitably focus on components of the course and the 
logistics of implementation, then they are poised for disintegration over time. If the key task of course design is simply identification of curriculum elements and how they might be divided and addressed in each corner of the course, then they will lack the glue to hold them together. When this happens, students will endure fractured and fragmented learning experiences. If the identification of overarching themes, linking pillars of experience, cross course connections and developmental nexuses are afterthoughts, then the atomised conceptualisation will leave gaps that can only widen. Therefore, a good curriculum design must consider cohesion elements alongside pragmatics from its original conception. If achieved, students become part of an informed and ongoing process where courses remain current and vital rather than always being somewhere along a continuum of birth, death and re-birth.

The next section outlines the tools that we believe may be helpful to focus and empower course leadership while strengthening the pragmatics of the course architecture. We suggest the identification of cohesion factors and the development of snapshot and connection trees.

\section{Cohesion Factors}

We propose that cohesion factors are fundamental in all curriculum design. A cohesion factor is something that enables course elements to be brought together. The five we have identified in our own practice and through observing the practice of others are: (a) setting parameters, (b) sequencing, (c) teaching approaches, (d) resources, and (e) assessment. The overarching cohesion factor in sustaining course cohesion is leadership which we will investigate later in this paper.

\section{Setting parameters}

Every course of study has sets of operational parameters that may be either external or internal to the institution. In Australia, all university courses are governed by the AQF (Australian Qualifications Framework). Identifying and explicating these parameters as a first step is absolutely vital. A broad yet specific environmental scan that evaluates contemporaneous contextual factors for the course design and also considers the future is essential. Key points to consider:

1. If the "new" course is being reconfigured from an existing course or is responding to identified shortfalls within an institution, then historical feedback from stakeholders must be consulted. Ignoring the past is a well known shortcut to repeating its mistakes.

2. If the proposed program of study is vocational or professionally oriented, then relevant professional accreditation guidelines need to be consulted. Further, given the desired portability of qualifications, it will also be necessary to consider accreditation guidelines of neighbouring regions and any international standards that may exist. Engagement with professional bodies and registering authorities to ascertain future directions for accreditation processes will ensure the program is not made redundant through a lack of vision or restrictive/inflexible design.

3. Over-arching parameters such as Graduate Attributes or Graduate Capabilities (Nelson, 2003) which are applicable in Australian higher education institutions must also be considered. These are generic skills relating to such factors as content knowledge, critical and creative thinking, problem-solving and communication.

4. A watermark or institutional brand for graduates will be important. Degree courses will also frequently carry an institutional stamp, for example, the Queensland University of Technology's badging as a university "for the real world" is enacted through its courses creating explicit links to industry.

5. Institutional parameters for University-wide or shared concerns need to be addressed. For example, there is considerable contemporary attention to the First Year Experience (FYE) where the specific needs of beginning students are foregrounded through a heightened scaffolding of learning. Similarly, there is attention to the notion of a capstone unit at the 
end of a course providing a culminating and synthesising experience for students before they enter their profession.

6. Consideration also needs to be given to contemporary research regarding effective teaching and learning in higher education, and efficacy of learning experience design for courses in the same field of education. Similarly, consideration needs to be given to the affordances of available technologies and how their informed adoption could alter and enhance students' learning experiences.

\section{Sequence}

Curriculum planning frequently begins with content selection and sequencing with a developmental model typically used to position topics within and across semesters. There is similarly a broad brush apportioning of time to differing aspects of content and a division of content into core or mandatory units of study and discretionary or elective units. Scheduled into this are field studies or other requisite activities usually positioned concurrent with relevant studies.

Sequencing becomes a cohesion factor when curriculum designers conduct vertical and horizontal mapping of content. If comprehensive, sequencing can be seen to align with the logical, temporal, and procedural cohesion seen as desirable in a computer program.

Ensuring that students have the required prerequisites to enter stages of their course programs involves a careful examination of the learning outcomes achieved for each unit of study, and a sense of linear development and sequential cohesion of desired graduate characteristics from $a b$ initio through to course completion. Multilayered sequencing is necessary with regard to content knowledge, critical thinking skill development, development of scholarship and analytical capabilities as well as demonstrable technical competencies. Each course outcome depends on multiple discrete experiences that link and overlap each other over time. Matrices that map key developmental trajectories through a course can become factors for holding the course together cohesively.

\section{Teaching approaches}

Teaching approaches can act as cohesion factors. A course may depend on a particular philosophy which encourages particular development of ways of knowing and discipline specific models for enquiry, for example, PBL (problem-based learning) or WIL (work integrated learning). As a result, it may be important to ensure approaches to learning, selection of learning activities and assessment practices all align with these epistemologies. Similarly, where learners are in distance mode or otherwise external to the university, digital technologies may act as a cohesive device, that is, the use of discussion forums or video/audio conferencing, between and within units of study.

\section{Resources}

Resources can provide cohesion. A prime example is where a course may share a textbook across units of study. This affords communicational cohesion because of shared ontology or universe of discourse allowing a singular lens to be brought to a discipline.

\section{Assessment}

Assessment can be a cohesion factor where there are common processes and a shared language, for example, a restricted number and agreed assessment type descriptors are used. Common processes range from the simple logistics of how student assignments are submitted and tracked, to agreed and consistent policies for extensions and marking scales. It may also be desirable to connect assessment throughout a course so that units of study progressively build their assessment around earlier work of students. Alternatively, to capitalise on concurrent learning, assessment for units of study that occur together in time across a course, may be integrated. 


\section{Snapshot and connection trees}

Snapshot and connection trees may be useful tools to assist in communicating how a course is held together. Each cohesion factor can be represented in a snapshot or connection tree thus showing its interdependence in the coherent course design.

We define a snapshot as a representation of the elements that link at a given point in a course design. For example, John Willison's Research Skill Development map outlines dimensions of student analytical and scholarship development as they progress through the years of a degree program (Willison, 2010). Each level of learning is like a snapshot. At any given stage of a students' journey through a program of study, they are often engaging with more than one part of the planned course. This is particularly true for students who are studying full time. A snapshot representation provides an impression of how these experiences contribute to each other. A snapshot captures how these experiences draw from and link with previous course experiences, and how they logically prepare students for the next stage in their learning and development. We propose that designing course elements that fit together at a particular stage of student development, and which rely on each other to build the desired characteristics for the students, is an important step in building course cohesion. Making these snapshots available to both students and faculty is important in maintaining course cohesion.

Connection trees refer to the ways learnt elements connect through a program of study. A connection tree may be represented in a tabular way, linking learning outcomes across the stages of a course, or they may be more like a mind map or decision tree, where achievement at one point links in to the next suite of learning outcomes. They show how higher level competencies, knowledges and characteristics expected in the later years study build from simple beginnings in a program of learning. A connection tree will show how an assessment program is designed to build unit learning outcomes for students that form a foundation for the learning outcomes and experiences for the next developmental stage.

These approaches allow the design of a program to be mapped. They assist faculty to identify the key design elements and therefore help them to understand how their work with students fits with the overall plan. They also provide a shorthand way of describing the decisions, constraints and affordances which led to the course being as it is. Constant reference to these planning designs is vital to avoid course cohesion drift. The cohesion factors we have described here cannot, in and of themselves, keep a course together. The missing factor is leadership which we chose to investigate through asking questions of colleagues responsible for course design and cohesion. Their responses are presented in the following section.

\section{Looking for leadership}

While the notional model of cohesion factors we were building had begun to take shape, we were also interested in matching this with how others had considered the problems of cohesion establishment and maintenance, and, further, how these pragmatic issues interfered or facilitated leadership for cohesion. From this, we developed research questions which we trialled with a small number of senior academics with responsibility for course design and cohesion. The questions are:

What factors work to ensure course cohesion in tertiary academic programs?

What factors act against course cohesion in tertiary academic programs?

What leadership approach attends most successfully to establishing and maintaining course cohesion in tertiary academic programs?

Given the nuanced factors influencing course design and management for tertiary institutions and Faculties, and the small population size for academic leadership in Australian tertiary institutions, this study lent itself more appropriately to qualitative rather than quantitative methodologies. The interpretivist/phenomenological methodology (Denzin \& Lincoln, 1994; Marton, 1986) selected for this study has been case study with a narrative enquiry approach (Riessman, 2008). 


\section{Participants}

Four senior academics from separate large Australian tertiary institutions in four different states/territories, were asked to respond to an email which requested their narrative textual (email) reflections on four short prompt questions that asked them to consider their experiences with influences for and against course cohesion. The academics were course or program coordinators, Associate Deans (Teaching and Learning), Heads of School, and/or Executive Deans of Faculties. Each was an Associate or full Professor, with accountability to their institution and to external accrediting bodies for course quality assurance. Two of the approached academics, to be referred to as Sally and Regina, responded. One also provided detailed input to supplement their initial textual response. This was captured with an audio recording enabling a fuller account of the issues for and against course cohesion from their perspective. Although a small sample, these respondents provided rich data and have given us cause to believe that the approach, including the wording of the prompt questions, has potential for further investigation.

\section{- Sally}

Sally is a tenured Associate Professor who has had the recent responsibility for the design of a suite of four-year Bachelor of Education programs for a large urban Australian Faculty of Education. Part of her design responsibility was to lead the accreditation progress for the courses through the local/regional accrediting body for teacher registration. To support her design work, Sally developed a detailed framework to describe the complex interrelationships between themes of study and year of progress through the programs, and related assessment design. This framework nested unit learning outcomes within course learning outcomes that directly aligned to required discipline standards outlined by the registration authority. Once Sally had completed the design work and succeeded in attaining accreditation, she left the program teaching team for a sabbatical period. She now teaches into the program with responsibility for a single thread or theme across the four years, and has now been given leadership of another area in the Faculty.

\section{- Regina}

Regina is currently a Senior Research Fellow and full tenured Professor. She has recently moved from being the course coordinator of a four-year undergraduate course which she led for five years at a large urban Australian university. The course was offered within a large Faculty comprising four schools. Her course was one of a connected set of pre-service teacher education programs and combined units which were delivered by academics from different Schools within the Faculty, working under different workload formulas, and to different Head of School line managers. Core units (approximately 30\% of the unit offerings) in her course were shared by other courses. In her position as course coordinator, she was not afforded the opportunity to design the learning sequences from scratch, but rather was required to develop the course team and lead course structure renovation and innovation to respond to external and internal reform agendas.

\section{Prompt material}

Each participant was asked to respond to these emailed questions:

What have you seen that has worked to hold a course together over time?

What factors have you seen that worked against course cohesion over time?

How might a course leader work to bring and keep course elements together?

What are the key indicators that a course is working as a unified program of study and development?

As noted, both Sally and Regina responded with extensive textual responses to each of the questions. A few days after submission of her written responses, Sally asked if she could submit an audio file of her verbal responses to the questions, and supplementary ideas she thought might further illuminate her perspective. This was submitted a few days later, was transcribed using conventional discourse coding techniques (e.g. Freebody, 2003). The transcript was returned to Sally for her confirmation of the accuracy of the transcript and to provide an opportunity for her to clarify or amend the record where she felt necessary to best reflect her intentions. This process is one we intend to replicate in a later broader study. 


\section{Results}

Sally

Sally's key message for establishing and maintaining cohesion was for team building leadership based on a strong communication model:

“... Course coordinator (should) make sure staff are aware of course as a whole and the place they play in it. [program] meetings, and course meetings with staff and students.” (Sally1, email).

She felt that communication across a course was often weak and served to undercut course cohesiveness. This was illustrated in her audio anecdote:

"we had a meeting and someone came along went round the table and she was asked 'what's your unit' and her reply was 'it's a bunch of crap'. I said 'I'm sorry, can I just go back to that - the reason that unit was put there was blah blah blah blah', but no-one had told her that and she was just making up stuff to go in it" (Sally2, audio submission).

Sally also identified that knowledge about the other activities and goals of the course academic team and their units and teaching was important but insufficient to maintain cohesion. She thought that knowledge of general curriculum design at a scholarly level for all teaching team members and knowledge of the contextual influences and likely trajectories were also important:

"Also the course coordinator .. and probably everybody really ..I know I seem to be loading everything on the Course Coordinators but they need knowledge of curriculum design, and they need to think about how the course hangs together as a whole, what is missing and what works best where, somebody needs to be involved at that level, what needs to happen and keep an eye on markets - what's happening with each course when it goes to change.” (Sally3, audio)

While she thought that each of the academic team needed solid understanding of general curriculum design, she thought that the responsibility for ensuring this rested with the course coordinator:

"all staff should have knowledge about tertiary curriculum design - nobody really does that unless the course coordinator drives it at the level of the course." (Sally4, audio)

Sally thought the opposite of these course leadership actions worked to force a course apart:

"Opposite of above. Course coordinator too busy with other duties ... program development takes back seat. New staff come in and nobody briefs them on where their unit sits.” (Sally5, email)

Her audio submission effectively listed a number of activities that could be employed to facilitate communication across a course academic team ranging from team meetings, focus groups with students, websites, informal "get togethers," and course panel plenary sessions.

Sally responded to questions asking for indicators of course cohesion. Although she mentioned monitoring of student and staff complaints and student attrition and employment levels, she was also able to explain more nuanced measures of course cohesion more related to course knowledge and engagement indicators:

"Students make connections between units, and across years. All teaching staff have something to contribute to discussions about course ... and undertake course improvement 'projects'. Students show growing sense of responsibility, confidence, and are keen to go. ... demonstrate strong evidence of (meeting) outcomes. Fourth years take an interest in first years etc. Discussions in 
tutorials and content in assignments show students are making connections across their program....I dunno? (sorry?)” (Sally6, email)

In summary, Sally's perspective was that course cohesion was dependent on course leadership which focused on course knowledge building, team building and communication.

\section{Regina}

It is of interest that Regina also thought that course cohesion was dependent on the quality of the leadership based on a clear communication strategy:

"Clear and regular information sharing with staff and students. Use of working parties for specific activities/issues with clear agendas. Forums in which to share course development ideas and T\&L practices.” (Regina1, email)

Regina added though, that the communication strategy would only be successful if the course coordinator had "people skills".

The place of course knowledge was also paramount to Regina:

"Good (and ongoing) orientation for new staff so they are not wandering down the corridor to ask a colleague (who might have been around for a long time but knows bugger all) what to do about some course -related matter" (Regina2, email)

Shared ongoing mapping and renovation was suggested by Regina as a tool for the team to consider and reconsider the connections and developments across a course, for example "The assessment map across course (sic) also helps..... Use an assessment map and make this publically available” (Regina3, email)

Regina had quite a different view of the prominent factors that dismantle course cohesion as compared to Sally. Rather than course coherence being predominantly due to an investment in leadership and mapping, Regina felt that poorly conceived and enacted course level policy was a key factor working against cohesion:

"Weak or non-existent policy upon which to make decisions. Dysfunctional committees (participants not reading material, not preparing for meetings, not taking action as proposed)" (Regina4, email)

This combined with unprofessional behaviour such as:

"Staff who make up their own rules and contravene university policy (e.g. with respect to unit assessment and standards for student conduct)." (Regina5, email)

\section{And just a lack of professional investment:}

"Unit coordinators who may not strive for consistency in what tutors are teaching students tutors with their own agendas left to choose their own adventure .... when student assessment is not coordinated" (Regina6, email)

Planning and preparation for the future was also raised by Regina, as it was by Sally, as a key factor in maintaining cohesion:

"Know the discipline area. Know what is coming up over the horizon in terms of big issues that may need to be taken up in courses. Consult regularly with other CCs (course coordinators). Work to develop sound policy to guide decisions.” (Regina7, email) 
When considering the indicators of success in achieving and/or maintaining cohesion, Regina focussed on student satisfaction and performance measures:

"Students are generally satisfied with the course. Students understand and can explain why the course is structured and conducted the way it is.... students can make links between previous study and current study - knowledge, skills and attitudes are transported and developed through the course.” (Regina8, email)

However, like Sally, Regina also acknowledged traditional measures of course success such as reduced attrition, and a lessening level of student initiated complaints, and a high level of graduate employment.

In summary, both Sally and Regina called for a focus on consultative course leadership, investment in communication strategies that served to inform all about the structure and goals of the course, and monitoring of course engagement, satisfaction indicators and course learning outcome attainments.

Both Sally and Regina were academic leaders and experienced course designers and coordinators. This in itself almost predisposed them toward describing the key elements for course cohesion in terms of the quality and vision of the leadership. In essence, they were critiquing themselves and their approach to team building and shared goal development. Questions about the facilitation of course leadership, would have been interpreted as questioning their own performance as leaders, and so would have naturally evoked comments regarding their fundamental values and tools for academic leadership. Since they were the designers of the courses as well, it was unlikely that questions about cohesion would have lead them to criticise the initial course architecture, because they would have embraced the initial excitement and promise of the course design process, and their disappointment would have rested with the extent to which the promise was not realised through constraints on their leadership.

\section{Discussion and conclusion}

The responses from the two senior academics confirmed the pivotal role of leadership in maintaining course cohesion. Specific reference was made to a shared vision - particularly relating to the cohesion factors of sequence, teaching approaches and assessment - reinforced through differing communication forums (see Regina1, Regina2, Sally1, Sally2, Sally5). This would imply that communication may warrant being a standalone cohesion factor with a role in both course development and management. This sharing should also extend to students who see their course as being a meaningful whole (Regina8, Sally6).

Leadership also implies an ongoing understanding of the parameters considered in the initial course design (Sally3) and more broadly of the principles of course designs (Regina7, Sally3, Sally4). Interestingly, what might have been perceived as a cohesion factor, that is, coordinating individuals, teams or committees, might also work against cohesion (Regina4, Regina6) where such groups are not aware of or sufficiently committed to maintaining course structures. Similarly, individuals may be, by choice or omission, left to their own devices and create idiosyncratic versions of courses or assessment schedules, what Regina called "choose their own adventure" (Regina5, Regina6, Sally5). This commentary supports our own observations noted at the beginning of this article where we spoke of how the initial enthusiasm, sense of renewal and genuine collaboration dissipate over time.

In addition to this, the academics made reference to devices akin to the snapshot and connection trees we listed as potential cohesion factors (Regina3) indicating that these may have a role in both creating and sustaining cohesion. The missing component here is that, once built, these guides must be made public and reviewed as an ongoing 'map' for both students and faculty.

This paper has tentatively investigated the factors leading to course cohesion drift and those that can be identified for establishing and maintaining course cohesion. The two case studies reported 
as narratives present different perspectives on the key influences for cohesion, but considered together provide a fairly comprehensive view of the elements underpinning course cohesion.

It would appear that both effective course leadership and robust design architecture are influences for cohesion. These elements work together to enable ongoing development, innovation and responsive renovation of courses without cohesion collapse. Consideration of cohesion factors, connection trees and snapshots are potential tools for bringing together leadership and design elements for course cohesion.

The main aim, for us, is to stop seeing course design as a process of birth and death, of new courses being tabula rasa, and of reining in the perpetual motion of curriculum renewal and replacing it with a gentler process more respectful of the creative input of those involved, more attuned to the experience of our students and more amenable to change from both within and outside of the university. This paper is our first step in identifying the generic factors which will bring us closer to cohesive coherent courses which continue to make sense over time, and which, although they may change, do not lose their way.

\section{References}

Biggs, J. (1999). Teaching for quality learning at university. Buckingham, UK: Society for Research into Higher Education \& Open University.

Biggs, J., \& Tang, C. (2007). Teaching for quality learning at university: What the student does. $\left(3^{\text {rd }}\right.$. ed.). Maidenhead, UK: Society for Research into Higher Education \& Open University.

Denzin, N. K., \& Lincoln, Y. S. (1994). Handbook of qualitative research. Beverly Hills, CA: Sage.

Freebody, P. (2003). Qualitative research in education: Interaction and practice. London: Sage.

Johnson, R. (1994). The second language curriculum. Cambridge, UK: Cambridge University Press.

Flinders University. (2009). Curriculum development. Retrieved from: http://www.flinders.edu.au/teaching/teaching-strategies/curriculumdevelopment/curriculumdevelopment.cfm

Marton, F. (1986). Phenomenography: A research approach to investigating different understandings of reality. Journal of Thought, 21, 28-49.

Massam, M. (2004). Teaching, learning and reflective practice. Retrieved from: http://www.ala.asn.au/conf/2004/massam.pdf

Nelson, G. (2003). Our universities: Backing Australia's future. Canberra, Australia: Commonwealth of Australia.

Riessman, C.K. (2008). Narrative research in the human sciences. Thousand Oaks, CA: Sage.

Shulman, L.S. (1993). Teaching as community property: Putting an end to pedagogical solitude. Change Magazine (November 6-7). Retrieved from: http://72.5.117.129/publications/pub.asp?key=43\&amp;subkey=797

Willison, J., O’Regan, K., \& Murdoch, P. (2006). Research skills development framework. The University of Adelaide. Retrieved from: http://www.adelaide.edu.au/clpd/rsd/framework 